\title{
Awareness on Oral Hygiene Measures Among Pregnant Women -A Cross Sectional Survey
}

\author{
Anubhav Das', Sangeetha² and Revathi Duraisamy \\ ${ }^{1}$ Saveetha Dental College, Saveetha institute of medical and technical Saveetha \\ Dental College \& Hospitals sciences, Saveetha University, Chennai-600077, India \\ ${ }^{2}$ Reader Department of Prosthodontics, Saveetha Dental College \& Hospitals, Saveetha Institute \\ of Medical and Technical Sciences, Saveetha University, Chennai-600077, India \\ ${ }^{3}$ Senior Lecturer, Department of Prosthodontics, Saveetha Dental College \& Hospitals, Saveetha \\ Institute of Medical and Technical Sciences, Saveetha University, Chennai-600077, India
}

\section{ABSTRACT}

Dental care during pregnancy is extremely important. From keeping up with daily oral hygiene, to monitoring changes in the young mouth, the more in-tune you are with your oral health the healthier your baby will be. During pregnancy, there is a change in the hormone levels which makes the oral cavity more vulnerable to microorganisms and plaque, both of which gingivitis during pregnancy. This can put you at greater risk for tooth decay and gum disease. The need to maintain good oral hygiene status among pregnant women is very important for proper pregnancy outcomes.Maintenance of oral health during pregnancy has been recognised as an important public health issue worldwide. Therefore, it is of utmost importance to create awareness among pregnant women regarding oral hygieneA survey was conducted for 50 pregnant women, from Poonamallee Govt. Hospital, Kilpauk Govt. Hospital, a questionnaire was given to them which took into account of their age and for how many months they are undergoing pregnancy, did they undergone any dental treatment before or not, do they have any prevailing teeth problems or not and what all nutritional supplements are they taking, are they facing any gum related problems or not after becoming pregnant. Responses were obtained and analysis was done in the Statistical Product and service solutions (SPSS) software. After the survey was conducted it was seen that $56 \%$ of the patients were undergoing through the 3rd trimester of pregnancy. $62 \%$ of the patients brushed twice a day. 76\% of the patients did not undergo any dental treatment pre pregnancy. Only $28 \%$ have a problem of bad breath. 84\% of them were having gum related problems after becoming pregnant.So from this survey, we can conclude that gum related problems are very common after becoming pregnant, especially in the 2 nd trimester and most of them do not visit dentists for regular check up.

KEY WORDS: PERIODONTITIS; OESTROGEN; INFLAMMATION; PREGNANCY; TRIMESTER.

\section{ARTICLE INFORMATION}

*Corresponding Author: revathid.sdc@saveetha.com

Received 15th June 2020 Accepted after revision 10th August 2020

Print ISSN: 0974-6455 Online ISSN: 2321-4007 CODEN: BBRCBA

Thomson Reuters ISI Web of Science Clarivate Analytics USA and Crossref Indexed Journal

$$
\begin{gathered}
\text { Clarivate } \\
\text { Analytics }
\end{gathered}
$$

NAAS Journal Score 2020 (4.31) SJIF: 2020 (7.728)

A Society of Science and Nature Publication,

Bhopal India 2020. All rights reserved.

Online Contents Available at: http//www.bbrc.in/

Doi: $h t t p: / / d x . d o i . o r g / 10.21786 / b b r c / 13.7 / 75$ 


\section{INTRODUCTION}

Pregnant women are more susceptible to periodontal diseases due to hormonal changes which happen during pregnancy. A few studies have shown that poor oral hygiene during pregnancy may be associated with adverse pregnancy outcomes, such as premature birth and low birth weight. Prevention of oral and dental problems during pregnancy is possible through having pregnant women expressing appropriate knowledge, attitude and perception(Christensen, Jeppe-Jensen and Petersen, 2003).Pregnancy is a unique period in a woman's life and is characterised by various physiological changes, which may affect the oral health. Women's life cycle changes present challenges to the oral health care profession.

Hormonal changes influence the periodontal and oral tissue to respond to various local factors creating various diagnostic and therapeutic dilemmas(Barak et al., 2003)(Al Habashneh et al., 2005)(Muralidharan et al., 2019)(Thomas, Middleton and Crowther, 2008). Pregnancy gingivitis and periodontitis is the most common oral condition observed among pregnant women(Fakheran, Saied-Moallemi and Khademi, no date). During pregnancy, there is an increased level of hormones oestrogen and progesterone. These hormones have been found to affect periodontal disease progress and wound healing. Both these hormones lead to gingival vascularisation and decreased immune response. Some studies reveal, during pregnancy, there is an increase in some types of microorganisms (Provetella species) which utilise the steroidal hormones of pregnancy for their growth and development.

These increase the bleeding tendency of the gums and worsen gingival inflammation. As a result, pregnant women have severe gingival inflammation even with low plaque levels(George et al., 2013).Various attempts should be made to focus on pregnant women's dental health, as studies have shown that women attend health care centres more often during their pregnancy; therefore, the primary goal of a dentist should be to evaluate the mother's oral health during this crucial period in order to improve the wellbeing of the infant(Anandakumar and Sankari, 2016)(Mokeem, Molla and Al-Jewair, 2004). It is very essential to take care of oral hygiene during pregnancy.

Previously our department has published extensive research on various aspects of prosthetic dentistry ('Evaluation of Corrosive Behavior of Four Nickelchromium Alloys in Artificial Saliva by Cyclic Polarization Test:An in vitro Study', 2017a; Ganapathy, Kannan and Venugopalan, 2017a; Jain, 2017a, 2017c; Ranganathan, Ganapathy and Jain, 2017a; Ariga et al., 2018a; Gupta, Ariga and Deogade, 2018a; Anbu et al., 2019a; Ashok and Ganapathy, 2019a; Duraisamy et al., 2019a; Varghese, Ramesh and Veeraiyan, 2019a)('Evaluation of Corrosive Behavior of Four Nickel-chromium Alloys in Artificial Saliva by Cyclic Polarization Test:An in vitro Study', 2017b; Ganapathy, Kannan and Venugopalan, 2017b;
Jain, 2017b, 2017d; Ranganathan, Ganapathy and Jain, 2017b; Ariga et al., 2018b; Gupta, Ariga and Deogade, 2018b; Anbu et al., 2019b; Ashok and Ganapathy, 2019b; Duraisamy et al., 2019b; Varghese, Ramesh and Veeraiyan, 2019b), this vast research experience has inspired us to research about this study to create awareness about the importance of oral hygiene during pregnancy

\section{MATERIAL AND METHODS}

A survey was undertaken with 50 pregnant women from Poonamallee Govt. Hospital and Kilpauk Govt. Hospital of Chennai from june 2019 to march 2020. Inclusion criteria was all the 50 pregnant women were pregnant for the second time and approached personally and asked their consent for participating in this survey, following which they were asked to take the survey in an online survey platform which consisted of a set of 7 questions, it took into account everyone's age and which trimester they are going through, are they having any gum inflammation or not after pregnancy and are they having any problem of bad breath or not, what all nutritional supplements are they taking, whether they brush their teeth twice a day or not, do they visit dentist for regular checkups or not. Each pregnant patient was given a mobile phone to answer for the survey questions. The results were analyzed through pie-charts, after importing them to excel. Questionnaire as follows :

1. You belonged to which trimester of pregnancy?

2. How many times do you brush your teeth in a day?

3. Have you ever underwent dental treatment before?

4. Is there a presence of bad breath?

5. Do you have prevailing Dental problems?

6. Do you go for a regular dental check up?

7. Do you have gum related problems after pregnancy?

Figure 1: It was seen that $56 \%$ of them were between 16-25 years old, 36\% of them were between 26-30 years and $8 \%$ were between $31-40$ years. $32 \%$ of them were undergoing the 1st trimester denoted by blue, 56\% of them were undergoing the 2 nd trimester denoted by red and $12 \%$ were going through the 3 rd trimester denoted by green.

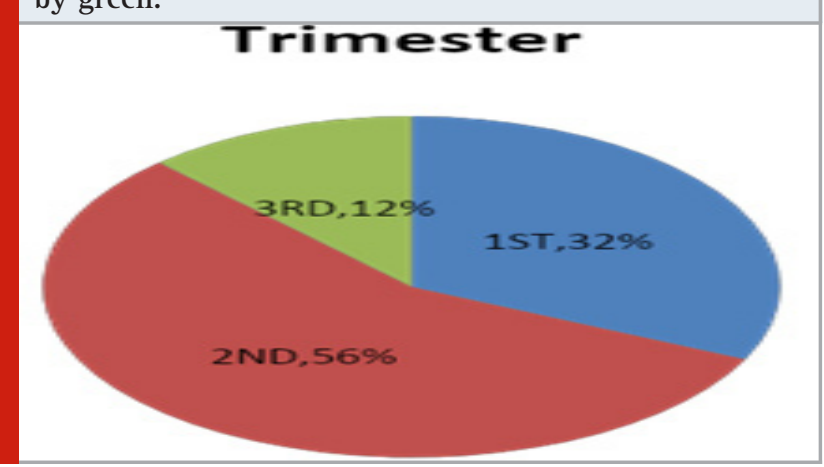




\section{RESULTS AND DISCUSSION}

The data obtained were statistically analysed using pie charts.

Other studies have shown the same group of participants (Silk et al., 2008)(Jeffcoat et al., 2001).

Figure 2: It was seen that $26 \%$ of them brush at least once a day denoted by blue, $62 \%$ of them brush twice a day denoted by red and $12 \%$ of them brush more than twice a day denoted by green.

\section{No. of times brusing done per day}

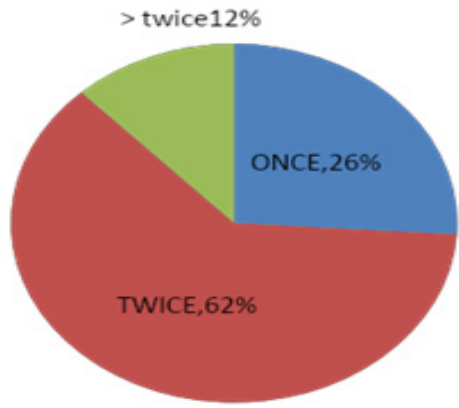

Though higher values are reported from other studies (López, Smith and Gutierrez, 2002; Barak et al., 2003; Christensen, Jeppe-Jensen and Petersen, 2003; Alwaeli and Al-Jundi, 2005; von Arx and Lozanoff, 2016)

Figure 3: It was seen that $24 \%$ of them went through dental treatment before pregnancy denoted by blue, 76\% of them did not undergo any dental treatment before pregnancy denoted by red.

\section{Underwent dental treatment?}

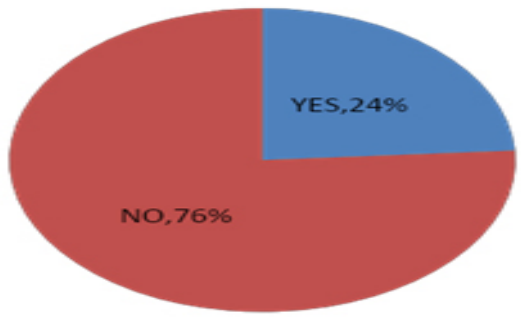

In contrast to this finding of our study, approximately half in one of the study and 58.4\% in another study who reported having dental problems went to a dentist for treatment(Gaffield et al., 2001)(Gaffield et al., 2001; Ranasinghe et al., 2017).

These findings are in agreement with previous studies(Amin and ElSalhy, 2014; Vamos et al., 2015; Kumar et al., 2017; Musskopf et al., 2018).

It is contradictory, to the findings of previous study where most of the pregnant women had dental problems(Rateitschak, 1967; Coonrod et al., 2008; Migliorini et al., 2014)
It shows how ignorant they are about their oral hygiene status. Other studies have also been associated with these ignorance and lower oral care during pregnancy (Azofeifa et al., 2014) (Timothé et al., 2005). This could be due to low socioeconomic status and educational status among pregnant patients in that geographical area.

Figure 4: It was seen that $28 \%$ of them are having a problem with bad breath denoted by blue, $72 \%$ of them are not having any bad breath denoted by red.

\section{Problem of bad breath ?}

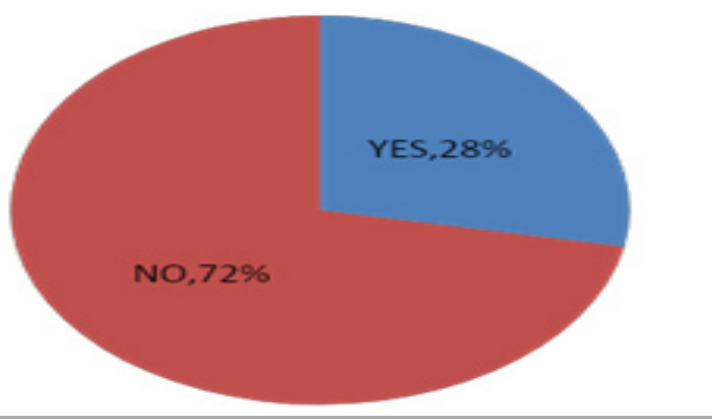

Figure 5: It was seen that $12 \%$ of them are having prevailing tooth problems denoted by blue and $88 \%$ of them are not having any tooth problems denoted by red.

\section{Any prevailing dental problem?}

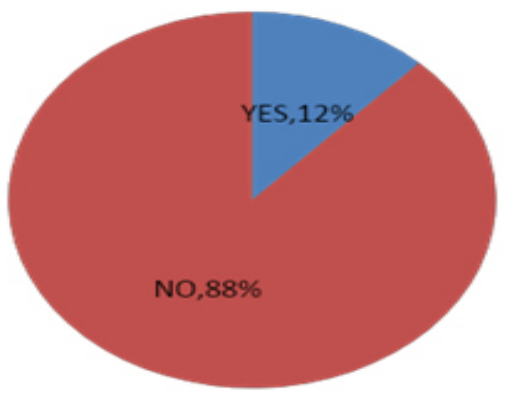

Figure 6: Only 4\% of them do visit dentist for a regular dental check-up denoted by blue, $96 \%$ of them do not go for any regular dental checkups denoted by red.

regular dental check ups

Y YES NONO

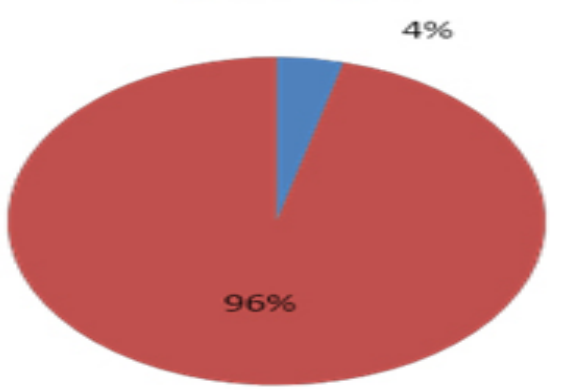


Figure 7: 84\% of them are having swollen gums after pregnancy denoted by blue, $16 \%$ of them don't have any gum related problems after pregnancy denoted by red, it shows that gum swelling and other problems are very common in pregnant women.

\section{Gum related problems after} pregnancy?

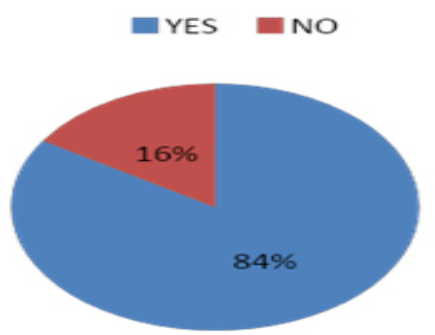

Previously, in a study involving 2009-11 data from the Pregnancy Risk Assessment Monitoring System (PRAMS) in Hawaii, it was seen that half of the study population had their teeth regularly cleaned before pregnancy compared with only one-fourth of the study population during pregnancy(Mattheus et al., 2016). In a study, 23 to $35 \%$ of pregnant women went to the dentist during pregnancy, 12 to $25 \%$ suffered from oral health issues, and, of those with a problem, only 45 to 55\% received care (Gaffield et al., 2001). The study further found that maximum women thought poor oral health during pregnancy was normal. In a study involving 2004-08 data ,26\% of the study population reported that they needed dental care during their pregnancy, but only $58.4 \%$ of them sought care(Ranasinghe et al., 2017).

It was seen that gum problems are very regular during pregnancy, most of them do not go to dentists for their dental check ups regularly [12, 13, 14, 15].Previous studies done also state that gum problems presents most commonly towards the end of the first trimester of pregnancy and becomes normal mostly after delivery, occurring in approximately $0.2 \%$ to $9.6 \%$ of pregnancies. (Lin et al., 2007; Rezazadeh et al., 2014)

Limitations: The limitations of this study was, no association has been done between systemic health and pregnancy, small sample size and also no association has been done between age and pregnancy.

Future Scope: Future scope can be a further study which takes into account a large population from various ethnicities, finding out associations between age and pregnancy, systemic health and pregnancy.

\section{CONCLUSION}

Within the limitations of the study it can be concluded that maintaining good oral hygiene among pregnant women is necessary for healthy delivery of the child. Gum related problems occur mostly during pregnancy, proper care should be taken during pregnancy and one should visit dentists for proper dental care during pregnancy.

\section{ACKNOWLEDGEMENTS}

I would like to show our gratitude to the Director of Academics, DR. Deepak Nallasamy Veeraiyan, Saveetha Institute of Medical and Technical Sciences, for sharing his pearls of wisdom with us during the course of this research, and we thank the reviewers for their so-called insights. We are also immensely grateful to Department of Prosthodontics,Saveetha Dental College for their comments on an earlier version of the manuscript, although any errors are our own and should not tarnish the reputations of these esteemed persons.

Conflict of interest: There is no conflict of interest.

\section{REFERENCES}

Al Habashneh, R. et al. (2005) 'Factors related to utilization of dental services during pregnancy', Journal of clinical periodontology, 32(7), pp. 815-821.

Alwaeli, H. A. and Al-Jundi, S. H. (2005) 'Periodontal disease awareness among pregnant women and its relationship with socio-demographic variables', International journal of dental hygiene, 3(2), pp. 74-82.

Amin, M. and ElSalhy, M. (2014) 'Factors affecting utilization of dental services during pregnancy', Journal of periodontology, 85(12), pp. 1712-1721.

Anandakumar, A. S. and Sankari, R. (2016) 'Awareness about Periodontal Disease and Its Association with Systemic Disease among Medical Practitioners: A Pilot Study', Journal of Contemporary Dentistry, pp. 104-107. doi: 10.5005/jp-journals-10031-1152.

Anbu, R. T. et al. (2019a) 'Comparison of the Efficacy of Three Different Bone Regeneration Materials: An Animal Study', European journal of dentistry, 13(1), pp. 22-28.

Anbu, R. T. et al. (2019b) 'Comparison of the Efficacy of Three Different Bone Regeneration Materials: An Animal Study', European journal of dentistry, 13(1), pp. 22-28.

Ariga, P. et al. (2018a) 'Determination of Correlation of Width of Maxillary Anterior Teeth using Extraoral and Intraoral Factors in Indian Population: A Systematic Review', World Journal of Dentistry, 9(1), pp. 68-75.

Ariga, P. et al. (2018b) 'Determination of Correlation of Width of Maxillary Anterior Teeth using Extraoral and Intraoral Factors in Indian Population: A Systematic Review', World Journal of Dentistry, 9(1), pp. 68-75. von Arx, T. and Lozanoff, S. (2016) Clinical Oral Anatomy: A Comprehensive Review for Dental Practitioners and Researchers. Springer.

Ashok, V. and Ganapathy, D. (2019a) 'A geometrical method to classify face forms', Journal of oral biology and craniofacial research, 9(3), pp. 232-235.

Ashok, V. and Ganapathy, D. (2019b) 'A geometrical 
method to classify face forms', Journal of oral biology and craniofacial research, 9(3), pp. 232-235.

Azofeifa, A. et al. (2014) 'Oral health conditions and dental visits among pregnant and nonpregnant women of childbearing age in the United States, National Health and Nutrition Examination Survey, 1999-2004', Preventing chronic disease, 11, p. E163.

Barak, S. et al. (2003) 'Common Oral Manifestations During Pregnancy: A Review', Obstetrical \& Gynecological Survey, pp. 624-628. doi: 10.1097/01. ogx.0000083542.14439.cf.

Christensen, L. B., Jeppe-Jensen, D. and Petersen, P. E. (2003) 'Self-reported gingival conditions and self-care in the oral health of Danish women during pregnancy', Journal of clinical periodontology, 30(11), pp. 949-953.

Coonrod, D. V. et al. (2008) 'The clinical content of preconception care: infectious diseases in preconception care', American journal of obstetrics and gynecology, 199(6 Suppl 2), pp. S296-309.

Duraisamy, R. et al. (2019a) 'Compatibility of Nonoriginal Abutments With Implants: Evaluation of Microgap at the Implant-Abutment Interface, With Original and Nonoriginal Abutments', Implant dentistry, 28(3), pp. 289-295.

Duraisamy, R. et al. (2019b) 'Compatibility of Nonoriginal Abutments With Implants: Evaluation of Microgap at the Implant-Abutment Interface, With Original and Nonoriginal Abutments', Implant dentistry, 28(3), pp. 289-295.

Evaluation of Corrosive Behavior of Four Nickelchromium Alloys in Artificial Saliva by Cyclic Polarization Test:An in vitro Study' (2017a) World Journal of Dentistry, 8(6), pp. 477-482.

Evaluation of Corrosive Behavior of Four Nickelchromium Alloys in Artificial Saliva by Cyclic Polarization Test:An in vitro Study' (2017b) World Journal of Dentistry, 8(6), pp. 477-482.

Fakheran, 0., Saied-Moallemi, Z. and Khademi, A. (no date) 'Oral Health Related Quality of Life during Pregnancy and Postpartum: A systematic review'. doi: 10.21203/rs.2.11594/v1.

Gaffield, M. L. et al. (2001) 'Oral health during pregnancy: an analysis of information collected by the pregnancy risk assessment monitoring system', Journal of the American Dental Association , 132(7), pp. 1009-1016.

Ganapathy, D. M., Kannan, A. and Venugopalan, S. (2017a) 'Effect of Coated Surfaces influencing Screw Loosening in Implants: A Systematic Review and Meta-analysis', World Journal of Dentistry, 8(6), pp. 496-502.

Ganapathy, D. M., Kannan, A. and Venugopalan, S. (2017b) 'Effect of Coated Surfaces influencing Screw Loosening in Implants: A Systematic Review and Meta-analysis', World Journal of Dentistry, 8(6), pp. 496-502.
George, A. et al. (2013) 'The oral health status, practices and knowledge of pregnant women in south-western Sydney', Australian Dental Journal, pp. 26-33. doi: 10.1111/adj.12024.

Gupta, P., Ariga, P. and Deogade, S. C. (2018a) 'Effect of Monopoly-coating Agent on the Surface Roughness of a Tissue Conditioner Subjected to Cleansing and Disinfection: A Contact Profilometric Study', Contemporary clinical dentistry, 9(Suppl 1), pp. S122S126.

Gupta, P., Ariga, P. and Deogade, S. C. (2018b) 'Effect of Monopoly-coating Agent on the Surface Roughness of a Tissue Conditioner Subjected to Cleansing and Disinfection: A Contact Profilometric Study', Contemporary clinical dentistry, 9(Suppl 1), pp. S122S126.

Jain, A. R. (2017a) 'Clinical and Functional Outcomes of Implant Prostheses in Fibula Free Flaps', World Journal of Dentistry, 8(3), pp. 171-176.

Jain, A. R. (2017b) 'Clinical and Functional Outcomes of Implant Prostheses in Fibula Free Flaps', World Journal of Dentistry, 8(3), pp. 171-176.

Jain, A. R. (2017c) 'Prevalence of Partial Edentulousness and Treatment needs in Rural Population of South India', World Journal of Dentistry, 8(3), pp. 213-217.

Jain, A. R. (2017d) 'Prevalence of Partial Edentulousness and Treatment needs in Rural Population of South India', World Journal of Dentistry, 8(3), pp. 213-217. Jeffcoat, M. K. et al. (2001) 'Periodontal infection and preterm birth: results of a prospective study', Journal of the American Dental Association , 132(7), pp. 875-880.

Kumar, G. et al. (2017) 'Oral health of pregnant females in central India: Knowledge, awareness, and present status', Journal of Education and Health Promotion, p. 102. doi: 10.4103/jehp.jehp_146_16.

Lin, D. et al. (2007) 'Persistently High Levels of Periodontal Pathogens Associated With Preterm Pregnancy Outcome', Journal of Periodontology, pp. 833-841. doi: 10.1902/jop.2007.060201.

López, N. J., Smith, P. C. and Gutierrez, J. (2002) 'Higher risk of preterm birth and low birth weight in women with periodontal disease', Journal of dental research, 81(1), pp. 58-63.

Mattheus, D. et al. (2016) 'The Association Between Socio-demographic Factors, Dental Problems, and Preterm Labor for Pregnant Women Residing in Hawai'i', Hawai'i journal of medicine \&t public health: a journal of Asia Pacific Medicine \&t Public Health, 75(8), pp. 219-227.

Migliorini, S. E. et al. (2014) 'Patients With Skin Diseases And Oral Manifestations: The Importance of Medical And Dental Treatment', Oral Surgery, Oral Medicine, Oral Pathology and Oral Radiology, p. e182. doi: 10.1016/j.oooo.2013.12.172.

Mokeem, S. A., Molla, G. N. and Al-Jewair, T. S. (2004) 'The prevalence and relationship between periodontal 
disease and pre-term low birth weight infants at King Khalid University Hospital in Riyadh, Saudi Arabia', The journal of contemporary dental practice, 5(2), pp. 40-56.

Muralidharan, S. et al. (2019) 'Oral Health Literacy and Oral Health Knowledge among 2,263 First-time Pregnant Urban Women: A Cross-sectional Questionnaire Study', The Journal of Contemporary Dental Practice, pp. 1029-1032. doi: 10.5005/jp-journals-10024-2657.

Musskopf, M. L. et al. (2018) 'Oral health related quality of life among pregnant women: a randomized controlled trial', Brazilian oral research, 32, p. e002.

Ranasinghe, N. et al. (2017) 'Oral Healthcare during Pregnancy: Sustenance of care and implications for future practice', Asian Pacific Journal of Health Sciences, pp. 20-27. doi: 10.21276/apjhs.2017.4.3.5. Ranganathan, H., Ganapathy, D. M. and Jain, A. R. (2017a) 'Cervical and Incisal Marginal Discrepancy in Ceramic Laminate Veneering Materials: A SEM Analysis', Contemporary clinical dentistry, 8(2), pp. 272-278.

Ranganathan, H., Ganapathy, D. M. and Jain, A. R. (2017b) 'Cervical and Incisal Marginal Discrepancy in Ceramic Laminate Veneering Materials: A SEM Analysis', Contemporary clinical dentistry, 8(2), pp. 272-278.

Rateitschak, K. H. (1967) 'Tooth mobility changes in pregnancy', Journal of periodontal research, 2(3), pp.
199-206.

Rezazadeh, F. et al. (2014) 'Oral Mucosal Disorders in Pregnant versus Non-Pregnant Women', Dentistry Journal, pp. 134-141. doi: 10.3390/dj2040134.

Silk, H. et al. (2008) 'Oral health during pregnancy', American family physician, 77(8), pp. 1139-1144.

Thomas, N. J., Middleton, P. F. and Crowther, C. A. (2008) 'Oral and dental health care practices in pregnant women in Australia: a postnatal survey', BMC Pregnancy and Childbirth. doi: 10.1186/1471-2393-813.

Timothé, P. et al. (2005) 'Dental care use among pregnant women in the United States reported in 1999 and 2002', Preventing chronic disease, 2(1), p. A10.

Vamos, C. A. et al. (2015) 'Oral health promotion interventions during pregnancy: a systematic review', Community dentistry and oral epidemiology, 43(5), pp. 385-396.

Varghese, S. S., Ramesh, A. and Veeraiyan, D. N. (2019a) 'Blended Module-Based Teaching in Biostatistics and Research Methodology: A Retrospective Study with Postgraduate Dental Students', Journal of dental education, 83(4), pp. 445-450.

Varghese, S. S., Ramesh, A. and Veeraiyan, D. N. (2019b) 'Blended Module-Based Teaching in Biostatistics and Research Methodology: A Retrospective Study with Postgraduate Dental Students', Journal of dental education, 83(4), pp. 445-450. 